\title{
One plausible reason for the change in ENSO characteristics in the 2000s
}

\author{
Vladimir N. Stepanov ${ }^{1}$ \\ vlnst@hotmail.co.uk
}

\section{Abstract}

It is well known that El Niño Southern Oscillation (ENSO) causes floods, droughts in different regions of the Earth and the collapse of fisheries in the tropical Pacific, therefore forecasting of ENSO is an important task in climate researches. Variations in the equatorial warm water volume of the tropical Pacific and wind variability in the western equatorial Pacific has been considered to be a good ENSO predictor. However, in the 2000s, the interrelationship between these two characteristics and ENSO onsets became weak. This article attempts to find some plausible explanation for this.

The results presented here demonstrate a possible link between the variability of atmospheric conditions over the Southern Ocean and their impact on the ocean circulation leading to the amplifying of ENSO events. It is shown that the variability of the atmospheric conditions upstream of Drake Passage can strongly influence ENSO events. The interrelationship between ENSO and variability in the equatorial warm water volume of the equatorial Pacific, together with wind variability in the western equatorial Pacific has recently weakened. It can be explained by the fact that the process occurred in the Southern Ocean recently became a major contributor amplifying ENSO events (in comparison with the processes of interaction between the atmosphere and the ocean in the tropics of the Pacific). Likely it is due to a warmer ocean state observed from the end of the 1990s that led to smaller atmospheric variability in the tropics and insignificant their changes in the

\section{Southern Ocean.}

Keywords: ENSO; the Southern Ocean; numerical modelling.

${ }^{1}$ This work has been carried out while the author was working at Department of Meteorology, University of Reading 


\section{Introduction}

29 Forecasting of ENSO events is an important task in climate research because ENSO events have a

30 global influence weather systems: both in the tropical Pacific (where the ENSO events occur) and at

31 moderate/high latitudes (e.g., Lau et al. (2005), Nicholls et al. (2005), Mokhov and Smirnov (2006),

32 Müller and Roecker (2006), Stepanov et al. 2012, demonstrated the influence of warm ENSO on the

33 weather in the Northern Hemisphere). Many publications provide evidence that the interactions

34 between high latitudes and the tropics can impact the ENSO variability (e.g., Pierce et al. (2000),

35 Vimont et al. (2003), Dong et al. (2006), Chang et al. (2007), Alexander et al. (2008), Wang et al.

36 (2012), Terray (2011)).

37 As was noted by Stepanov (2009 a, b), the above mentioned teleconnections can be explained by

38 the fact that ENSO events could be considered as a consequence of changes in the global meridional

39 atmospheric circulation rather than a local phenomenon in the tropics. The link between the tropics

40 and high latitudes can exist due to interactions between the tropics and the mid-latitudes, which

41 influence the high latitudes and vice versa. For example, warming (cooling) of the upper ocean layer

42 in the tropics (which can be related, for example, to the seasonal cycle, or consequence of the

43 frequent occurrence of the weak El Niño) leads to an increase (decrease) in the warming of the

44 troposphere in a region where atmospheric mass upwells (the Pacific Ocean is the largest ocean and

45 therefore has the largest contribution to these changes). This means that warmer (colder) upgoing air

46 from the tropical zone is transported by the Hadley circulation cell to the subtropics, which slows

47 down (accelerates) the air motion in the downwelling branch of the Hadley cell and then leads to

48 weakening (intensification) of the wind in the mid-latitudes, which then lead to similar changes in the

49 high latitudes. Therefore many teleconnections between ENSO and weather at distant regions from

50 the tropical Pacific have been found, and the paper will pay an attention to the link between the wind

51 processes over the Antarctic Circumpolar Current (ACC) and ENSO events (Stepanov, 2009a,b). 
The intensity of Walker circulation is associated with the Southern Oscillation Index (SOI) that describes fluctuations in the difference of the surface air pressure anomalies between Tahiti $\left(17^{\circ} 52^{\prime} \mathrm{S}\right)$ and Darwin $\left(12^{\circ} 25^{\prime} \mathrm{S}\right)$. During warm ENSO conditions there is an eastward displacement of the Walker circulation, resulting in high atmospheric pressure and cooler SST conditions over the western Pacific. During cold ENSO conditions there is an intensification of normal Walker circulation conditions, producing low atmospheric pressure and warmed SSTs in the western Pacific (http://www.bom.gov.au/lam/climate/levelthree/analclim/elnino.htm). Thus, the SOI can be considered as atmospheric component of ENSO due to the variability of atmospheric forcing in the western equatorial Pacific. Fig. 1a shows 1989-2008 correlations of zonally averaged monthly sea

61 level pressure (SLP) with SOI-index taken with negative sign, which was taken from http://www.cpc.ncep.noaa.gov/data/indices. We clearly see seasonality and that SOI-index leads the $\underline{\text { SLP change in low latitudes. However, as Fig. } 1 \text { (b-d) demonstrates, the change of the zonally }}$ averaged SLP occurs in phase with the change of the meridional gradient of the SLP. Likely the meridional gradient change of the SLP is a primary source of the SLP variability in the low latitudes that then in its turn, results in to the next SLP change in the tropics in the zonal direction, i.e. SOI index change (Fig. 1a). The above figures show that even for annual cycle the change of the meridional gradient of the atmospheric pressure in low latitudes is more important for the variability

69 of atmospheric pressure here than SOI-index variability, since the correlations of zonally averaged $\underline{\text { SLP with the meridional gradient of the atmospheric pressure is higher and the last can lead the }}$ variability of the zonally averaged SLP, which, in its turn, can impact the meridional gradient of the and $12^{\circ} \mathrm{S}$ (Fig. 1d) is about -0.6 (all the correlations presented by the paper are statistically significant

75 with a probability of $95 \%$, which was determined through the effective number of degrees of freedom 76 following Bretherton et al. (1999)). According to the absolute values of correlation coefficients 
between NINO and SOI indexes $(\leq 0.7)$, less than $50 \%$ of the NINO variability can be explained by changes of atmospheric forcing in the western equatorial Pacific. Thus, it is likely that the development of ENSO events can be due to some other mechanism, e.g. the global meridional atmospheric circulation change that can affect both high and low latitudes. Thus we can assume that the changes in the global meridional atmospheric circulation begun in April (i.e. time when the

82 initiation of ENSO begins) can lead to the changes both in the tropics and in the Southern ocean

83 simultaneously, and some link between atmospheric processes in the Southern ocean and ENSO can

84 exist (Stepanov (2009a).

$85 \quad$ Numerical experiments presented by Stepanov $(2009 \mathrm{a}, \mathrm{b})$ have demonstrated that the variability of

86 wind forcing over the ACC, together with the effect of bottom topography, lead to the appearance of

87 anomalies in pressure and density in the Southern Ocean. The appearance of these anomalies is

88 caused by the short time scale variability of the meridional mass fluxes in the Pacific sector of the

89 Southern Ocean north of $47^{\circ} \mathrm{S}$, of which the average value from July to September is estimated to be

90 greater than $2000 \mathrm{Gt}\left(1 \mathrm{Gt}=10^{9} \mathrm{t}\right)$. This variability of the oceanic mass in the Pacific Ocean is

91 negatively significantly correlated with the wind forcing over the ACC. As a measure of wind

92 strength the SAM index (Southern Hemisphere Annular Mode) has been used. This is determined as

93 the normalized difference between the zonal-mean SLP between $40^{\circ} \mathrm{S}$ and $70^{\circ} \mathrm{S}$ (obtained from the

94 National Oceanic and Atmospheric Administration).

95 The density anomalies near the regions where the strong variability of the meridional mass fluxes

96 in the Pacific sector of the Southern Ocean is observed, can be transported to the low latitudes of the

97 Pacific Ocean by means of the wave mechanism described by Ivchenko et al. $(2004,2006)$ and

98 Blaker et al (2006). Here they interact with the stratification and can cause variations in the

99 inclination of the thermocline in the tropical Pacific, which, in turn, can facilitate more intense

100 development of ENSO effects (Stepanov, (2009 a,b)). Therefore there is also high correlation (with 
101

102

coefficient of $\sim 0.8$ ) between the variability of the oceanic mass in the Pacific Ocean and ENSO events (Stepanov, 2009 a).
The above mentioned variability of the meridional mass fluxes in the Pacific sector of the

Southern Ocean is due to mass exchange occurring between the Southern Ocean and Pacific regions at periods of 30-100 days, which is determined by the balance of wind stress by form stress (a pressure difference across topographic obstacles) in Drake Passage, together with the inverse barometer response to atmospheric pressure (see details in Stepanov and Hughes (2006)).

Alvarez Garcia et al. (2006) identified three classes of ENSO events on the basis of numericat modelling. The first two classes are characterized by well known mechanisms: the first class is described by a model of a delayed oscillator, when a negative feedback is formed between the propagation of equatorial waves and tropical sea surface temperature (SST) anomalies (see, for example, Suarez and Schopf (1988)); the second class is described by the model of a recharge/discharge oscillator, in which variability of tropical wind stress leads to variation of thermocline inclination due to fast wave processes (see, for example, Jin (1997)). The third class of ENSO events found by Alvarez Gareia et al. (2006) is characterized by the relatively fast development of these events (less than nine months after the appearance of wind anomalies in the western part of the Equatorial Pacific). This class confirms the conclusion described by Kessler (2002) that ENSO events are perturbations relative to a stable climatic state, and an external pulse, i.e. not part of the dynamic ENSO cycle, is required to amplify the ENSO event. Stepanov (2009 a,b) considered the possibility that the variability of meridional fluxes in the Pacific sector of the Southern Oeean (caused by the atmospheric variability over the Antaretic Cirempolar Current (ACC) and effects of the bottom topography and coastline shape) can be such a pulse (in addition to the variability of western winds in the tropics). 

paradigm for ENSO (see, for example, Jin (1997)), McPhaden, (2003, 2006), found some ENSO precursors in observation data: it was shown that variation in the equatorial warm water volume of

129 the tropical Pacific and wind variability in the western equatorial Pacific precedes ENSO by two to 130 three seasons and can be a useful ENSO predictor. A similar approach was proposed by Clarke and 131 Van Gorder, (2003) who used zonal wind stress over the Indo-Pacific tropics.

132 However Horii et al. (2012) have shown that the robust predictability of these predictors for 133 ENSO has changed in the 2000s. Before 2000, during two decades, the increase/decrease of the warm 134 water volume of the equatorial Pacific (recharge/discharge phase of the recharge/discharge oscillator) 135 together with strong/weak wind in the western equatorial Pacific preceded warm (El Niño) and cold 136 (La Niña) ENSO events by two to three seasons. While in the 2000s, the interrelationship between 137 these predictors and following ENSO became weak, especially for the ENSO events after 2005. 138 According to Horii et al. (2012) these changes may be caused by frequent occurrences of the "warm139 pool El Niño", which is characterized by SST anomalies centered in the central equatorial Pacific 140 (Larkin and Harrison (2005), Ashok et al. (2007), Kao and Yu (2009), Kug et al. (2009), and Lee and 141 McPhaden, (2010)), compared with that during 1980-2000. Under these conditions, the tropical 142 temperature anomalies are weak and the discharge phase of the recharge/discharge oscillator is not 143 significant. Under these conditions, the tropical temperature anomalies are weak and the discharge 144 phase of the recharge/discharge oscillator is not significant. Therefore the frequent occurrence of the warm-pool El Niño in the 2000s cannot provide discharged conditions that prevent the development 146 of significant cold ENSO events.

147 No reasons have been mentioned by Horii et al. (2012) to explain why the conventional ENSO 148 events have been recently displaced by the "warm-pool El Niño". Oscillator mødel paradigm for 149 ENSO (e.g., Suarez and Schopf 1988; Battisti and Hirst 1989; Weisberg and Wang 1997; Jin (1997)) 
is now widely accepted. This paradigm assumes eastward propagating Kelvin waves as the main

factors that provide the negative feedback that brings about the phase change. However it means that

sometimes eastward propagating Kelvin wave can also facilitate the development of ENSO rather

eppose the growth of its developing (e.g., see Wang et al. (2012)). The comparison of the time series

of the NINO3 (SST averaged in area of $\left.5^{\circ} \mathrm{N}-5^{\circ} \mathrm{S} ; 150^{\circ} \mathrm{W}-90^{\circ} \mathrm{W}\right)$ and NINO4 (SST averaged in area of $5^{\circ} \mathrm{N}-5^{\circ} \mathrm{S} ; 160^{\circ} \mathrm{E}-150^{\circ} \mathrm{W}$ ) indexes (www.cpc.ncep.noaa.gov/data/indices), as a measure of the shown), demonstrates that both indexes are varied almost in phase, but the amplitudes of the variability are different: the amplitude of NINO3 index can be up to 2 times larger (before 2000) than

159 NINO4. It is reasonable to think that NINO4 describes a primary source of some factor forcing the 160 onset of ENSO events_(that exists and after 2000), while NINO3 is a combination effect of the 161 primary source and changes due to the beginning of ENSO onset in the central Pacific, i.e. the

162 subsequent interaction between the atmosphere and ocean in the tropics (that has changed/modified

163 after 2000)a cross-correlation analysis presented by Ashok et al. (2007) confirms that the variability

164 of NINO4 index leads NINO3). It is likely that the subsequent changes in the Walker circulation cell canould significantly amplify ENSO development in this region located close to land prior to the

$166 \underline{2000 s}$. The results presented in this article will lead us to the conclusion that the wind processes over

167 the ACC, and particularly the atmospheric conditions upstream of Drake Passage, can strongly

168 influence the ENSO events (i.e. we should pay an attention to non-tropical factor too). Therefore

169 when the development of conventional ENSO (characterized by NINO3) prevails, a westward

170 migration of the eastern equatorial Pacific SST anomaly pattern is observed from the South American

171 ceast inte the central equatorial Pacific. While in the central Pacific, NINO4 signal can be attributed

172 only to the "ocean" impact. This suggests that other forcings also can influence the ENSO onsets

173 (e.g., see Kessler (2002), Stepanov (2009a, b)). 
Many publications provide evidence that the interactions between high latitudes and the tropics ean impact the ENSO variability (e.g., Pierce et al. (2000), Vimont et al. (2003), Dong et al. (2006),

176 Chang et al. (2007), Alexander et al. (2008), Wang et al. (2012), Terray (2011)). For example, Wang et al. (2012) have shown that the winter SST anomalies in the western North Pacific influence the development of wind anomalies over the equatorial western Pacific triggering oceanic Kelvin waves, which propagate eastward and initiate the developments of ENSO. However, not only teleconnections between different regions of the Pacific can impact the ENSO. Dong et al. (2006) demonstrated from global coupled ocean atmosphere modelling that some teleconnection exists between the Atlantic and ENSO: the warm phase of the Atlantic Multidecadal Oscillation leads to at weaker phase of the El Niño development. These authors supposed that this oceurs due to the fast processes in the atmosphere, which transfer the influence of the Atlantic to the tropies of the Pacific Ocean through an "atmospheric bridge." Numerical models and observations in the Southern Ocean demonstrate a statistically significant correlation between the processes near the Antarctic continent and in the tropical regions both with positive and negative lags of approximately a few months long. The analysis of the data of observations by Simmonds and Jacka (1995), Yuan and Martinson (2000), Kwok and Comiso (2002) demonstrate that the location of the Antaretic sea ice spreading boundary 190 is strongly correlated with the ENSO events on time scales of a few months: a correlation is observed between the ENSO events and the location of the boundary of the Antarctic sea ice spreading when the ENSO event either leads or lags with respect to the variability of the sea ice. Yuan and Martinson 193 (2000) explained the latter correlation by the existence of some atmospheric teleconnection between Antarctica and the equatorial Pacific. Recently Terray (2011) also suggested that there is link 195 between extra tropical atmospheric forcings in the southern hemisphere and ENSO. However, the model results reported by Ivchenko et al. (2004, 2006), Blaker et al. (2006) and Stepanov (2009 a,b)

197 lead us to suppose that the role of the ocean in the transfer process of seasonal signals from high 198 latitudes to the tropics can be even more important than was considered earlier. The results presented 
in this article lead to the conclusion that the wind processes over the ACC, and particularly the atmospheric conditions upstream of Drake Passage, can strongly influence the ENSO events.

the fact that ENSO events could be considered as a consequence of changes in the global meridional atmospheric circulation rather than a loeal phenomenon in the tropies. The link between the tropies and high latitudes can exist due to interactions between the tropics and the mid latitudes, which influence the high latitudes and vice versa. For example, warming (cooling) of the upper ocean layer in the tropics (which can be related, for example, to the seasonal cycle, or consequence of the frequent occurrence of the weak warm poøl El Niño) leads to an increase (decrease) in the warming of the troposphere in a region where atmospheric mass upwells (the Pacific Ocean is the largest ocean and therefore has the largest contribution to these changes). This means that warmer (colder) upgoing air from the tropical zone is transported by the Hadley circulation cell to the subtropics,

211 which slows down (accelerates) the air motion in the downwelling branch of the Hadley cell and then

212 leads to weakening (intensification) of the wind in the mid-latitudes, which then lead to similar 213 changes in the high latitudes. Therefore many teleconnections between ENSO and weather at distant regions from the tropical Pacific have been found. Therefore it is assumed in the paper that the ehanges in the global meridional atmospheric circulation begun in April can lead to the changes both in the tropies and in the Southern ocean simultaneously, and some link between atmospheric processes in the Southern ocean and ENSO can exist. describes fluctuations in the difference of the surface air pressure anomalies between Tahiti (17052'S) and Darwin $\left(12^{\circ} 25^{\prime} \mathrm{S}\right)$. During warm ENSO conditions there is an eastward displacement of the Walker circulation, resulting in high atmospheric pressure and cooler SST conditions over the western Pacific. During cold ENSO conditions there is an intensification of normal Walker 
(http://www.bom.gov.au/lam/climate/levelthree/analclim/elnino.htm). Thus, the SOI can be considered as atmospheric component of ENSO due to the variability atmospheric forcing in the western equatorial Pacific. Fig. 1a shows 19892008 correlations of zonally averaged monthly sea level pressure (SLP) with SOI-index taken with negative sign, which was taken from http://www.cpe.ncep.noaa.gov/data/indices. We clearly see seasenality and that SOI-index leads the SLP change in low latitudes. However, as Fig. 1 (b-d) demonstrates, the change of the zonally averaged SLP occurs in phase with the change of the meridional gradient of the SLP. Likely the meridional gradient change of the SLP is a primary source of the SLP variability in the low latitudes that then in its turn, results in to the next SLP change in the tropies in the zonal direction, i.e. SOI index change (Fig. 1a). The above figures show that even for annual cycle the change of the meridional gradient of the atmospheric pressure in low latitudes is more important for the variability of atmospheric pressure here than SOI index variability, since the correlations of zonally averaged SLP with the meridional gradient of the atmospheric pressure is higher and the last can lead the variability of the zonally averaged SLP, which, in its turn, can impact the meridional gradient of the SLP. After removing the seasonal cycle and low pass filtering with periods longer than 18 months, the correlation between SOI index and zonally averaged sea level pressure difference between $17^{\circ}$ and $12^{\circ} \mathrm{S}$ (Fig. 1d) is about -0.6. According to the absolute values of correlation coefficients between NINO and SOI indexes $(<0.7)$, less than $50 \%$ of the NINO variability can be explained by changes of atmospheric forcing in the western equatorial Pacific. Thus, it is likely that the development of ENSO events can be due to some other mechanism, e.g. the global meridional atmospheric circulation change that can affect high latitudes too: the stronger these changes, the stronger the effect that can be seen both in the low and high latitudes. 
subtropical latitudes of both hemispheres, and the impact of ENSO can be seen even in the Arctic (see, e.g. Stepanov et al. 2012).

It is well known that the maximmm phase of the development of the warm/cold ENSO-vents is observed in November-December, while the ENSO onset, i.e. time when the initiation of ENSO begins, is observed around April to June in many cases (e.g. Larkin and Harrison (2005)). This paper analyzes what factors can impact the development of the maximum phase of ENSO in the end of the year.

Section 2 briefly introduces the results of Stepanov (2009 a,b) demonstrating the impact of processes in the Southern Ocean on the amplifying mechanism of ENSO events due to variations in the wind forcing over the ACC, together with the effects of the topography and coastline. Section 3 describes the typical changes in the atmospheric conditions over the Southern Ocean a few months before the maximum phase of the development of ENSO and how these changes can be interrelated with ENSO events. Also the results of an empirical orthogonal function (EOF) analysis are presented

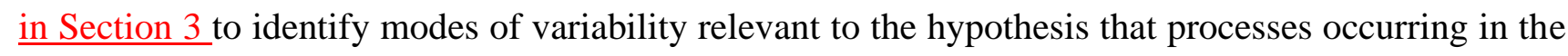
Southern Ocean can amplify ENSO events. Section 4 provides some discussion and conclusions about the link between the atmospheric and oceanic processes in the Southern Ocean and the maximum phase of the development of ENSO events.

\section{The transport processes in the Southern-Ocean and its relation- to ENSO \\ Numerical experiments presented by Stepanov $(2009 \mathrm{a}, \mathrm{b})$ have demonstrated that the variability of wind forcing over the ACC, together with the effect of bottom topography, lead to the appearance of anomalies in pressure and density in the Southern Ocean. The appearance of these anomalies is eaused by the short time scale variability of the meridional mass fluxes in the Pacific sector of the Southern Ocean north of $47^{\circ} \mathrm{S}$, of which the average value from July to September is estimated to be}


274 greater than $2000 \mathrm{Gt}$ (gigatons, $1 \mathrm{Gt}=10^{9} \mathrm{t}$ ). This variability of the oceanic mass in the Pacific Ocean is negatively correlated with the wind forcing over the ACC, significant at the 99\% level. As a measure of wind strength the SAM index (Southern Hemisphere Annular Mode) has been used. This is determined as the normalized difference between the zonal-mean SLP between $40^{\circ} \mathrm{S}$ and $70^{\circ} \mathrm{S}$ (obtained from the National Oceanic and Atmospheric Administration). Figure 2 presents curves that describe the transport variation through Drake Passage in $S_{V}\left(1 \mathrm{SV}=10^{6} \mathrm{~m}^{3} / \mathrm{s}\right)$ and the variability of

the oceanic mass, $\left.M(t)\right|_{\varphi=40 S}$, in the Pacific Ocean $\left(\left.M(t)\right|_{\varphi=40 S}-\int_{0}^{t} Q_{p}(t) d t\right)$ averaged from July to

September, which is caused by fluctuations of the meridional mass flux Qp-across $40^{\circ} \mathrm{S}$ calculated from the 20 year model data by Stepanov (2009a). The meridional mass fluxes have been obtained from a 1 degree barotropic ocean model by Stepanov and Hughes (2004) that was forced with 6 hr wind and atmospheric pressure forcings. High correlation (with coefficient of - 0.8 ) is observed between the minima and maxima of the variability of $M(t) H_{\varphi=40 s}$ in the Pacific sector and, eorrespondingly, the cold (La) and warm (El) ENSO events.

Antarctica can propagate to lower latitudes as fast barotropic Rossby waves almost without changes in their amplitude. Such waves propagate from Drake Passage to the equator only in a few weeks and then cross the entire Equatorial Pacific region during a few months. Although the Ivchenko-et at. (2004; 2006) results were obtained for simplified model topography, they have been confirmed by model results when models with real topography have been used (e.g., see Richardson et al (2005) and Blaker et al (2006)). Particularly Blaker et al 2006 show that the energy from the anomaly in the

Weddell Sea arrives at the western Pacific boundary via two ocean wave mechanisms. Barotropic Rossby waves transmit the signal directly across the Pacific Ocean (waveguide pattern of which was confirmed later by observations by Close and Naveira Garabato (2012)). Barotropic Kelvin waves 
away from the Southern Ocean. These waves propagate along topographic ridges which provide a eonnection between Antarctica and the land masses in the southern hemisphere.

Southern Ocean can cause short-period density anomalies near the regions where the strong

variability of these fluxes is observed, then by means of the wave mechanism described by Ivchenke

et al. $(2004,2006)$ and Blaker et al (2006), these anomalies can be transported to the low latitudes of

the Pacific Ocean. Here they interact with the stratification and can cause variations in the inclination

of the thermocline in the tropical Pacific, which, in turn, can facilitate more intense development of ENSO effects (Stepanov, (2009 a,b)). The results presented in Fig. 3 confirm this conclusion. Figure 3 shows the model temperature difference over a section along the equator for three time periods between perturbed and control calculations obtained by Stepanov (2009a) using 3-dimensional ocean eirculation model by Ibraev (1993) having approximately 1 -degree horizontal resolution and 19 depth levels (see details in Stepanov (2009a)). In the experiment with a perturbation in the Pacific sector of the Southern Ocean in the latitudinal zone between $47^{\circ}$ and $37^{\circ} \mathrm{S}$, a uniform by depth (i.e., barotropic) and latitude perturbation of the meridional velocity was specified for 90 days. It was obtained from the results of barotropic modelling by averaging the mean model barotropic meridionat velocity over the latitude in the zone between $47^{\circ}$ and $37^{\circ} \mathrm{S}$ and over the time from July to September of 1987, 1997, and 2002 (i.e., the periods preceding to maximum phase of the development of the warm ENSO events). The perturbation corresponded to the total equatorward meridional flux, but it was corrected in such a way that the total section flow would be zero. In a few days, owing to the processes described by Ivchenko et al. (2004, 2006) and Blaker et al (2006), positive and negative dipole shaped temperature anomalies appeared in the western part of the equatorial Pacific (not shown). These anomalies then moved along the equator to the eastern Pacific coast as a trapped Kelvin wave, which looks like an equatorial upwelling Kelvin wave propagating from the western to 
to the eastern Pacific. This type of Kelvin wave propagation agrees with the results of observations (see, for example, Delcroix et al. (1991)). This process leads to the elevation of the thermocline in the western part of the equatorial Pacific (from $130^{\circ}$ to $195^{\circ} \mathrm{E}$ ) and a depression in the eastern Pacific (Fig. 3). In the eastern (western) equatorial Pacific at depths of about $200 \mathrm{~m}$, the temperature anomalies reach approximately $0.3^{\circ} \mathrm{C}\left(-0.5^{\circ} \mathrm{C}\right)$. Since the temperature and salinity fields at the ocean surface in these numerical experiments corresponded to values averaged from June to August over a whole modeled 20 year period (from 1984 2003 HadCM3 model output) and were fixed, the development of surface and subsurface (within Ekman layer) anømalies was limited, since after the appearance of temperature anomalies in the tropics the subsequent interaction between the atmosphere and ocean in the model tropies is excluded. Nevertheless the zonal model temperature difference $\left(-1^{\circ} \mathrm{C}\right)$ in the tropical Pacific (which characterizes the thermocline stope here) is comparable with observation. velocity) leads to an opposite response of the equatorial Pacific: a warming in the western part and at cooling in the eastern part of the ocean; i.e., the thermocline descends in the western part of the equatorial Pacific and ascends in its eastern part.

Southern Ocean, as it has been studied by Stepanov and Hughes (2006), is due to mass exchange

341 eccurring between the Southern Ocean, Atlantic, and Pacific regions at periods of 30 100-days. Such 342 mass exchange is accompanied by global adjustment processes in the ocean, which are approximately 343 one month long. The main mass exchange occurs between the Southern and Pacific oceans, which is determined by the balance of wind stress by form stress (a pressure difference across topographic obstacles) in Drake Passage, together with the inverse barometer response to atmospheric pressure. 
approximately 65\% of total form stress on the ACC. Drake Passage is the most significant topographic feature among the three regions mentioned above, accounting for about $30 \%$ of the total form stress. The eastward directed wind stress leads to a decrease in the bottom pressure near the eoasts of Antaretica. At the same time, the balance of the wind stress over a topographic obstacle requires that the bottom pressure on the western side of the obstacle exceeds that on the eastern side. The wind variability over the ACC together with the above described topographic effects can lead to a variation in the meridional mass fluxes near bottom ridges that was demonstrated by Stepanov (2009 a,b) can impact the development of ENSO effects.

weakness is due to atmospheric pressure pattern blocking over the south-east Pacific. The change of atmospheric conditions over the ACC, and particularly over the region upstream of Drake Passage, ean substantially influence the bottom pressure on the western side of Drake Passage and the balance between wind stress and form stress in Drake Passage, which can impact the variability of the meridional mass fluxes in the Pacific sector of the Southern Ocean. The model effect of this variability on ENSO has just been described. The next section describes plausible reasons for the establishment of the atmospheric conditions over the ACC, which are favourable to amplify ENSO events from the Southern Ocean. Since, as it was shown by Stepanov (2009 a,b), there is a time lag of 46 months between the variation of $\left.M(t)\right|_{\varphi=40 s}$ in the winter spring season of the Southern Hemisphere and the maximum phase of ENSO-development (which is determined by the time needed to transport the density anomalies appearing in the Southern Ocean to low latitudes by means of at wave mechanism described by Ivchenko et al. $(2004,2006))$, we have to pay attention to the atmospheric variability that occurred about 4 months before the maximum phase of ENSO development. 

maximum phase of ENSO during warm periods?

375 As was mentioned early, the variability of the oceanic mass in the Pacific sector of the Southern

376 ocean is negatively correlated with the wind forcing over the ACC. We will see later that the wind

377 weakness is due to atmospheric pressure pattern blocking over the south-east Pacific. The change of

378 atmospheric conditions over the ACC, and particularly over the region upstream of Drake Passage,

379 can substantially influence the bottom pressure on the western side of Drake Passage and the balance

380 between wind stress and form stress in Drake Passage, which can impact the variability of the

381 meridional mass fluxes in the Pacific sector of the Southern Ocean, and hence ENSO events.

382 It is well known that the maximum phase of the development of the warm/cold ENSO events is

383 observed in November-December, while the ENSO onset, i.e. time when the initiation of ENSO

384 begins, is observed around April to June in many cases (e.g. Larkin and Harrison (2005)). Stepanov

385 (2009 a,b) has shown that there is a time lag of 4-6 months between the variation of the oceanic mass

386 in the Pacific sector of the Southern ocean in the winter-spring season of the Southern Hemisphere

387 and the maximum phase of ENSO development (which is determined by the time needed to transport

388 the density anomalies appearing in the Southern Ocean to low latitudes by means of a wave

389 mechanism described by Ivchenko et al. $(2004,2006))$. Therefore, we have to pay attention to the

390 atmospheric variability over the ACC that occurred about 4 months before the maximum phase of

391 ENSO development, i.e. we will analyze what factors can impact the development of the maximum

392 phase of ENSO in the end of the year.

393 Figures 4a2a-b show 1989-2011 mean SLP and its standard deviation. One can see that the field of

394 SLP has almost zonal structure over the ACC, while upstream of Drake Passage there is a high

395 variability of SLP. It means that sometimes in this region instead of a usual low atmospheric

396 pressure, an anticyclonic/cyclonic atmospheric circulation pattern can occur. 
From correlation between the monthly average SAM index and SLP (Fig. 4c드) one can see that the wind strength over the ACC is maximal when a low SLP is settled over the southern part of the

399 Southern Ocean, particularly near $250-260^{\circ} \mathrm{E}$, and vice versa. As we saw before the region upstream 400 of Drake Passage is important from the point of view of a balance between the wind stress and form 401 stress in Drake Passage that impacts the variability of the meridional mass fluxes in the Pacific sector 402 of the Southern Ocean. Therefore it is clear that a high atmospheric pressure settled over the 403 upstream of Drake Passage region changes the above balance in Drake Passage,ean "lock" Drake 404 Passage and together with the inverse barometer response to atmospheric pressure resulting in 405 equatorward meridional flux anomaly in the Pacific sector of the Southern Ocean that, as was shown 406 by Stepanov (2009_a,b), leads to conditions favourable to amplify warm ENSO. While a low pressure 407 developed over this region "accelerates" the wind over the ACC leading to poleward meridional flux 408 anomaly in the Pacific sector of the Southern Ocean resulting in the development of cold ENSO 409 (Stepanov (2009 a,b)).

410 The results presented in Fig. 5 confirm the above conclusion. This frigure 3 shows July411 September (Fig. 5a $\underline{3 \mathrm{a}-\mathrm{c})}$ ) and August-October (Fig. 5d $\underline{\mathrm{d} d}$ ) mean ERAInterim SLP anomalies (from the 412 1989-2011 mean) that are typical before the maximum phase of the development of warm (Fig. 5a3a413 b) and cold (Fig. 5e $\underline{3 c-d}$ ) ENSO events. Before warm ENSO reaches its maximum phase of 414 development, over the region upstream/near of Drake Passage high atmospheric pressure is settled 415 (Fig. 5a3a-b), while low SLP over this region is observed during the months preceding the maximum

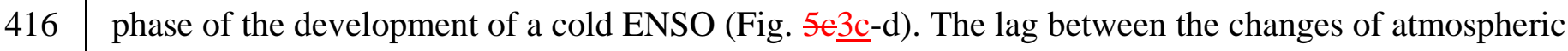
417 conditions over the ACC and maximum phase of ENSO development (3-6 months) is in accordance 418 with previous finding by Stepanov (2009a), e.g., the cold ENSO of 2007 has reached its maximum 419 phase of the development about 1-2 months later than ones in 1997, 1998 and 2002 (Fig. 5a3a-c), 420 therefore the negative SLP anomalies in the Southern Ocean near Antarctica have also been observed 421 later (Fig. 5d $\underline{3 \mathrm{~d}}$ ). Similar distribution of SLP anomalies has also been observed 3-5 months before the 
422 development of maximal phase of the ENSO in 1992, 1994, 1995, 2000, 2002, 2004, 2006, 2007 ,

423 2008, 2009 and 2010. Thus we see that atmospheric pressure patterns near/upstream of Drake

$424 \quad$ Passage region can be connected with ENSO events.

425 As was mentioned in section-Introductionz there is negative significant correlation between SAM 426 index and the variability of the oceanic mass in the Pacific sector of the Southern ocean $\left.M(t)\right|_{\varphi=40 S}$ 427 variability and-are significantly negatively correlated with NINO4 index, however the correlation 428 coefficient between SAM index and NINO4 index is low ( - 0.2$)$. Now when we realise that the 429 atmospheric conditions over the region upstream of Drake Passage can be erucial-significant for 430 whole ACC dynamiesENSO development, we can choose some other index. determined by the external forcing: for the case of weak (strong) wind, water masses move to the

equator (to the pole), to the north of these zones, while, south of these zones, they move to the pole (equator). This latitude zone of $47^{\circ}-48^{\circ} \mathrm{S}$ is the boundary between the regions, in which atmospheric eyclones south of $48^{\circ} \mathrm{S}$ and anticyclones north of $47^{\circ} \mathrm{S}$ propagate in the eastern direction over the ACC, generating fluctuations in the fields of the atmospheric pressure and wind velocity. Near the western coast of South America at $\sim 35^{\circ} \mathrm{S}$ there is a region of high atmospheric pressure (Fig. 4a2a) and an analysis of ERAInterim SLP shows that sometimes the area of high pressure penetrates to the south, in the region upstream of Drake Passage, erosses the latitude circle of $47^{\circ} \mathrm{S}$-between 260 $290^{\circ} \mathrm{E}$-and penetrates to the south, in the region upstream of Drake Passage. This position-path is in 443 accordance with the preferred propagation away from the Southern Hemisphere subtropical jet 444 waveguides indicated by Ambrizzi et al. (1995). Therefore the averaged sea level pressure anomaly 445 along $280^{\circ} \mathrm{E}$ between $35^{\circ} \mathrm{S}$ (the point marked by black cross on Fig. $4 \mathrm{e} 2 \mathrm{c}$ ) and $45^{\circ} \mathrm{S}, \Delta p$, can be a 446 good indicator for predicting such changes in atmospheric pressure field. 
In introduction it was supposed that NINO4 describes a primary source of some factor forcing the maximal development of ENSO events, which is due to ocean impact (NINO4 is the region where 449 changes of sea-surface temperature lead to total values around $27.5^{\circ} \mathrm{C}$, which is thought to be an 450 important threshold in producing rainfall in the tropics during ENSO). Therefore model ocean 451 characteristics obtained by Stepanov (2009a) have been compared with NINO4. However analysing 452 SLP field, variability of which reflects joint effect of the interaction between the ocean and 453 atmosphere, assumes using NINO index, incorporating similar impact. Therefore further we will 454 compare new characteristics found with NINO3.4 index (SST averaged in area of $5^{\circ}-5^{\circ} \mathrm{S} ; 170$ $455120^{\circ} \mathrm{W}$, www.cpc.ncep.noaa.gov/data/indices): it is the region that has large ENSO variability, and 456 that is close to NINO4 region where changes in local sea-surface temperature are important for 457 shifting the large region of rainfall typically located in the far western Pacific (though the comparison 458 results are similar for NINO4 too).

459 Figure 6- 4 shows normalized on their standard deviations anomalies monthly time series of 460 NINO3.4 index (black dashed) and $\Delta p$ (solid line) after applying 5 month running average procedure 461 (this procedure minimizes intra-seasonal noise, e.g., see Trenberth, 1997, note that this smoothing leads to that time series of the SOI index correspond very well with changes in ocean temperatures across the tropical Pacific). The black solid line is after subtraction of the seasonal cycle and is shifted 4 months forward. One can see that there is correspondence between peaks and troughs of

465 NINO-index with ones of $\Delta p$ curve that have been observed 3-5 months before the maximum phase 466 of the development of ENSO. The effect of atmospheric stochastic forcing, which always exists in 467 the processes of the interaction between the atmosphere and the ocean, led to wider time lag (3-5 468 months) between atmospheric changes in the Southern Ocean and the maximum phase of the 469 development of ENSO. The cases when NINO variability is in phase with/or slightly leads SLP ones 470 are seen only in the middle of years (these events are not considered by the paper), while at the 471 end/beginning of years (when the maximal developments of ENSO occur) SLP variability always 

months before maximal ENSO development).

474 The correlation coefficient between NINO3.4 index and $\Delta p$ time series for 1989-2011 period is 475 about 0.6 ( $\Delta p$ leads 4 months) and slightly varies for 1989-1999 (0.65) and 2000-2011 ( 0.5) periods 476 (all the correlations presented by the paper are statistically significant with a probability of $95 \%$, 477 which was determined through the effective number of degrees of freedom following Bretherton et 478 al. (1999)) (tests to determine the significance of difference in correlations between two periods 479 shows that this difference is not statistically significant). Later we will see that the EOF2 (Fig. 6b) 480 captures a zonal dipole pattern near Drake Passage presented in Fig. 3, with PC2 that is generally bigger and maxima of PC2 are wider prior to the 2000s than after (the same is true for NINO-index). 482 Therefore the correlation coefficient between the two indices for the period prior to the 2000s can be slightly greater than one after 2000, but, as was mentioned above, the difference is not statistically significant.

487 substantially changed: only over the upstream of Drake Passage region a high variability of the SLP 488 became more localized near Drake Passage, while in the tropical Pacific, the SLP variability

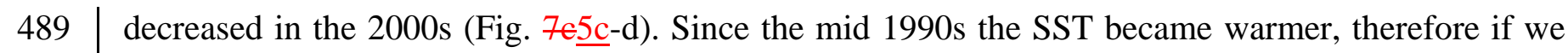
490 exclude from consideration the effect of the tropical cyclones (they rarely form within $5^{\circ}$ of the 491 equator (Henderson-Sellers et al, 1998) and their impact is significant in the northwest Pacific Ocean 492 basin only), it is reasonable to suppose that the variability of atmosphere in the tropics is decreased, 493 which does not allow developing conventional ENSO (described by NINO3 index). Results presented 494 on Fig. $7 \mathrm{e}$ c $\mathrm{c}-\mathrm{d}$ confirm this conclusion: before 2000 the variability of the SLP over the tropical 495 Pacific was higher than after: in the 2000s the atmospheric pressure patterns show weaker variability 496 ( $70 \%$ from 1989-2011 mean variability), while during the 1989-1999 period the area of higher 
atmospheric pressure variability (>100\% of 1989-2011 mean one) occupied almost the whole tropical

498 Pacific. However, the atmospheric variability in moderate and high latitudes of the southern

499 hemisphere did not change noticeably (Fig. 7a5a-b), which suggests that the effect of processes near

500 Antarctica still impact the tropical region of the Pacific Ocean with the same efficacy.

501 The interaction between the atmosphere and the ocean due to the existence of stochastic forcings

502 (e.g., see Flügel et al. (2004), Eisenman et al. (2005)) limits the predictability of ENSO (especially

503 "warm-pool El Niño", e.g. see Horii et al. 2012). The stochastic variability can lead to some

504 interannual changes in the tropics when weak tropical temperature anomalies can be superimposed

505 leading to substantial changes in the atmospheric meridional circulation. An example is 2006 when a

506 long warm period in the central tropics (during more than half of a year) provided discharged

507 conditions of the recharge/discharge ENSO oscillator at the beginning of 2007 (Horii et al. (2012)).

508 This cooling in the tropics led to the intensification of the meridional atmospheric circulation cell and

509 stronger wind over the ACC (the value of SAM index exceeded its standard deviation) when negative

510 SLP anomaly developed over the Southern Ocean (Fig. $5 \mathrm{~d} \underline{3 \mathrm{~d}}$ ) that finally resulted in the development

511 of the strong cold ENSO in 2007-2008. This ENSO had led to charged conditions of the

512 recharge/discharge ENSO oscillator and, as a result, the atmospheric variability in the tropical Pacific

513 has been increased after 2008. Figures 7 5 e-f show that 2000-2007 period had small SLP variability

514 (Fig. 7e $\underline{\text { e }}$ ), but 2008-2011 SLP variability in the western tropical Pacific (Fig. 7ffff) is comparable

515 with one before 2000 (Fig. 7e5c) that increases the impact of the tropical interactions on ENSO.

516 This variability is in agreement with NINO index variability. However, we should estimate the

517 variability of the difference, e.g. between NINO3.4 and NINO4 indexes, rather than the change of

518 absolute values themselves since the zonal gradient is significant for the intensity of Walker

519 circulation, which can be characterized by SOI index. Analysis shows that really standard deviation

520 of the difference between NINO3.4 and NINO4 for 1989-1999 period 2 times more than for 2000-

521 2011. Besides, there is a significant correlation of the difference between NINO3.4 and NINO4 with 
SOI for 1989-1999 (-0.51), while the same correlation for 2000-2011 is about zero. Thus, the significant correlation before 2000 and zero ones after 2000 says that the contribution of atmospheric component of ENSO due to the variability of atmospheric forcing in the western equatorial Pacific reduced, and hence the variability over the Southern ocean recently can contribute more in the processes of ENSO developments than it was before the 2000s. It is worth noting also that the significant correlations between SOI and NINO3.4 (-0.84) and NINO4 (-0.79) for 2008-2011 period are higher than during 2000-2007 (-0.58 and -0.47 , respectively for NINO3.4 and NINO4). The differences in correlations between two periods are statistically significant. The change of the above correlations is in agreement with results presented in Fig. 5 e-f. The above facts This fact explains why the correlation between the SOI and NINO also remains statistically significant during warm periods. It is likely that during warm periods the atmospheric variability in the tropics will be decreased again after onsets of series of the "warm-pool El Niño" events.

\subsection{The results of an EOF analysis of ERAInterim SLP field.}

The EOF analysis of atmospheric pressure patterns in the SE Pacific revealed an additional mechanism explaining the change in ENSO characteristics in the 2000s. The first, second and fifth leading EOF modes of monthly SLP field over the region of the Southern Ocean in the area south of $31^{\circ} \mathrm{S} ; 150-310^{\circ} \mathrm{E}$ are presented in Fig. 8a6a-c. The EOF1 pattern shown in Fig. 8a-6a captures the almost zonal structure of the SLP over the ACC. This mode explains about of $44 \%$ of the total variability over the region for the period between 1989 and 2011. The EOF2 (Fig. 8b 6 b) that explains about $14 \%$ of the SLP variability captures a zonal dipole pattern near Drake Passage that is in accordance with Fig. $5 \underline{3}$. Finally, the EOF5 mode (Fig. 8e $6 \mathrm{c}$ ) explaining 5\% of the SLP variability captures a meridional dipole pattern to the west of Drake Passage, which characterizes the variability of the strength of meridional shear of zonal wind. 
The EOF3 (explains less than $10 \%$ of the total variability) is omitted from a consideration, since

547 the EOF3 has a strong resemblance to the Pacific-South American pattern identified by Mo and Ghil

548 (1987), with principal component PC3 slightly correlated with NINO index (the highest correlation

549 ( 0.3) corresponds to the case when NINO index leads PC3 by 3 months), and it is strongly

550 associated with ENSO events (Sinclair et al. (1997); Carleton (2003)). The EOF4 ( 7\% of the total

551 variability) is not considered here because of its some resemblance to the EOF2 (high/low pressure

552 upstream and near of Drake Passage) and there is only a slight correlation between PC4 and NINO3.4

553 ( 0.3) for 1989-2001 period with PC4 leading NINO3.4 at about 3-4 months (for 2002-2011 PC4 and

554 NINO3.4 are not correlated at all, i.e. this mode cannot be a plausible reason for the change in ENSO

555 characteristics in the 2000s).

556 The time series of the normalized principal components (PCs) of EOF1, EOF2 and EOF5 together

557 with normalized NINO3.4 index are presented in Fig. 8d6d-f. A cross-correlation analysis between 558 these PCs and NINO3.4 index at different leads and lags for 1989-2011 period gives a maximum 559 correlations of $0.45,0.55$ and 0.38 with PCs leading NINO3.4 at 1,4 and 8 months respectively for 560 PC1, PC2 and PC5. However, we should note that correlations between PC1, PC2 and NINO3.4 for 561 whole 1989-2011 period and for 2 subperiods (1989-2001 and 2002-2011 periods) are comparable 562 (about 0.4 for PC1 and 0.5 for PC2), but the correlations between PC5 and NINO3.4 are different for 563 these different periods. The 2002-2011 period is a major contributor to the value of correlation 564 coefficient between PC5 and NINO3.4 for 1989-2011 period: 2002-2011 correlation is about 0.8, 565 while for 1989-2001 PC5 and NINO3.4 are not correlated at all. As was mentioned earlier, the EOF5 566 characterizes the strength of meridional shear of zonal wind over the region under consideration, 567 which defines the growth rate of the air jet instability over this region (see, e.g. Gill (1982), Paldor 568 and Dvorkin (2006)). The high correlation between PC5 and NINO3.4 means that air jet instability 569 over the region, leading to the formation of SLP patterns shown in Fig. $5 \underline{3}$, became to be a significant 
570 contributor to the development of maximal phase of the ENSO after 2002 with lead time of about 8

571 months, i.e., this event is coincident with the time of ENSO onset, Larkin and Harrison (2005).

572 Of course, it does not mean that the after change of PC5 it is needed about 4 months to lead to the 573 formation of SLP patterns shown in Fig. $5 \underline{3}$. The PC5 variability shows only that 8 months before the 574 development of maximal phase of the ENSO (i.e. in April, after boreal summer) there are 575 atmospheric conditions over the south-east Pacific sector of the Southern ocean, which characterize 576 higher meridional shear of zonal wind here. This variability is likely connected with global 577 meridional atmospheric circulation change in this time. This higher meridional shear of zonal wind in 578 April results in higher likelihood that the air jet instability will occur during Australian winter (July579 September) when the maximal variability of atmospheric characteristics is observed.

580 Many authors accept to take into account EOF modes just up to the 4-th order and they assume 581 that adding a few more does not modify the picture in any substantial way (e.g., see de Viron et al. 582 (2013)), that choice is based on Monte Carlo tests done by Overland and Preisendorfer (1982), who 583 showed that for their analysis only the first four PCs were significant. However, as follows from 584 Overland and Preisendorfer (1982), the significance of EOF modes depends on both length of observation data set and the choice of a number of eigenvalue statistics, $p$. Therefore to check a significance of our 5-th EOF mode, Monte Carlo test has been done similar to Overland and 587 Preisendorfer (1982). That is, it was verified if the eigenvalues of an EOF analysis of monthly SLP anomalies can be distinguished from those produced from spatially and temporally uncorrelated 589 random process. A random number generator was used to produce uncorrelated gaussian variables of 590 zero mean and unit variance and corresponding eigenvalues have been calculated (for computation of 591 the covariance matrix the value of variance is irrelevant). The experiment has been repeated one hundred times. Let us denote by $\lambda_{i}$ and $\delta_{i}^{r}$ eigenvalues computed from data sets corresponding to SLP 593 field and r-th Monte Carlo experiment, respectively (where $j(j=1, \ldots, p)$ is $j$-th EOF mode). Then the rule $\mathrm{N}$ that was used by Overland and Preisendorfer (1982) to distinguish observed mode from those 
595

596

597

598

599

600

601

602

603

604

605

606

607

608

609

610

611

612

613

614

615

616

617

618

619

620

621

622

produced by random processes, is given by the following: terminate the sequence of the normalized eigenvalues $T_{j}$, which is:

$$
\frac{p}{\underline{T}_{i}=\lambda_{j}\left(\sum \lambda_{j}\right)^{-1}}, j=1, \ldots, p,
$$

at the largest integer $j=m$ such that $T_{m}$ exceeds $U_{m}{ }^{95}$, where $U_{m}{ }^{95}$ is normalized eigenvalue calculated for random processes so that for fixed $j$ we have the following order: $U_{j}^{1} \leq U_{j}^{2} \leq \ldots \leq U_{j}^{100}$, where

$\frac{p}{\underline{U}_{j}^{r}=\delta_{j}\left(\Sigma \delta_{j}^{r}\right)^{-1}, j=1, \ldots, p,}$

$j=1 \quad r=1, \ldots, 100$.

Table 1 lists the normalized eigenvalues, $T_{j}$, and the ratio, $T_{j} / \underline{U}_{i}^{95}$, which determines the application of rule $\mathrm{N}$, for two choices of value of $p$. Both choices of $p$ are sensible. The choice of $p=22$ corresponds to the case when the first 22 EOF's modes explain about of $98 \%$ of the total SLP variability over the region for the period between 1989 and 2011. While the choice of $p=45$ is based on sampling "stochastic" eigenvalues with maximal values: each from the first 45 EOF's modes explains approximately the same value of the total stochastic variability (cumulatively they explain only about of $20 \%$ of the total stochastic variability). Perhaps, the second choice is more adequate. Note here that Overland and Preisendorfer (1982) have used higher values for $p: 56$ and 74 . Thus, the first five EOF's appear to contain meteorological information distinguished from noise, based upon rule $\mathrm{N}$, and the use of this mode in our analysis is justified.

The EOF analysis agrees with the previous cross-correlation analysis. So, PC1 is highly correlated with SAM index (with coefficient about -0.9) since EOF1 and SAM index describe the weakness and strength of wind over the ACC respectively. The EOF2 is in a good agreement with SLP anomaly pattern near Drake Passage presented in Fig. $5 \underline{3}$. Both $\Delta p$ and PC2 are significantly correlated with NINO3.4 (with the coefficient of $\sim 0.6$ and 0.5 respectively) with lead time of about 4 months. 


\subsection{Discussion and conclusions}

It is a generally accepted opinion that ENSO events are caused by the interaction processes

626 between the ocean and atmosphere in the tropics (excluding the recent paper by Terray (2011) who

627 pointed out the linkage between mid-latitude Southern Hemisphere climate and ENSO). It is well

628 known that the onset of ENSO events depends on the type of wind anomalies that are established in

629 the western equatorial part of the Pacific Ocean in the previous spring and summer. However, it was

630 shown by Lengaigne et al. (2004), these wind anomalies can trigger ENSO only under particular

631 favourable oceanic conditions. It was demonstrated by Eisenman et al. (2005) that the wind

632 anomalies considered in the tropics are a combination of joint effects of stochastic atmospheric

633 forcing and large-scale dynamics depending on the ENSO processes rather than being completely

634 external to the development of the ENSO events. Recently, Horii et al. (2012) have demonstrated that

635 because of some decadal changes in the variability of warm water volume of the equatorial Pacific

636 and wind variability in the western equatorial Pacific the robust predictability of these two predictors

637 for ENSO has changed in the 2000s: the lead time of two to three seasons observed before 2000 has

638 almost vanished and in the 2000s the variability of the warm water volume of the equatorial Pacific

639 and wind variability in the western equatorial Pacific occur almost in phase with ENSO development.

640 This suggests that other factors can impact the ENSO onsets.

641 This paper has considered a hypothesis based on the numerical results by Stepanov (2009 a,b) that

642 the atmospheric variability over the ACC can strongly influence amplifying ENSO events. This

643 hypothesis allows us to explain the breakdown in the 2000s of ENSO predictors proposed by

644 McPhaden (2003) through analysis of SLP fields. It was shown that the maximum phase of the

645 development of most ENSO events was associated with a change of the atmospheric conditions

646 upstream of Drake Passage in July-October when the variability of the atmosphere over the Southern

647 Ocean was-is especially strong. This variability, together with the effect of the bottom topography, 
648 leads to the changes of the balance between the wind stress and form stress in Drake Passage that,

649 together with the inverse barometer response to atmospheric pressure, result in the appearance of

650 anomalies in the fields of the pressure and density in the Southern Ocean. By means of the wave

651 mechanism described by Ivchenko et al. $(2004,2006)$ and Blaker et al (2006), these anomalies can be

652 transported to the low latitudes of the Pacific ocean, where they interact with the stratification via

653 Kelvin wave propagation and can cause variations in the inclination of the thermocline in the tropical

654 Pacific-(Fig. 3), which, in turn, can amplify ENSO event (Stepanov (2009 a,b)). In the 2000s, due to

655 warmer SST, more homogeneous dynamical conditions in the tropics developed (Fig. $7 \mathrm{~d} \underline{5 \mathrm{~d}}$ ), hence

656 the subsequent interaction between the atmosphere and ocean in the tropics after the beginning of

657 ENSO in the central equatorial Pacific is suppressed and a strong ENSO cannot be developed in the 658 eastern side of the tropical Pacific. As a result, frequent occurrences of the "warm-pool El Niño",

659 which is characterized by SST anomalies centered in the central equatorial Pacific, are observed 660 (Horii et al. (2012)). The high correlation between PC5 and NINO after 2002, EOF5 of which 661 characterizes the strength of the meridional shear of zonal wind over the region under consideration, 662 demonstrates that during warm periods the air jet instability over the region significantly impact 663 ENSO. Due to this instability in the region to the west of Drake Passage, anticyclonic/cyclonic 664 atmospheric circulation patterns can arise. It is likely that due to air jet instability during cold periods 665 (when the meridional shear of zonal wind is stronger) the area with high atmospheric pressure can be 666 developed over the region upstream of Drake Passage more frequently, therefore generally more 667 warm ENSO events than cold ones are observed. For example, the Oceanic Niño Index from 668 http://www.cpc.ncep.noaa.gov/products/analysis_monitoring/-ensostuff/ensoyears.shtml. This shows 669 that for 1950-2002 period 15 warm and 11 cold ENSO events have been observed respectively, while 670 after 2002 the numbers of warm and cold ENSO were the same. It is in agreement with the analysis 671 of PC2 and PC5 timeseries. Both timeseries are not symmetric with respect to the zero value. The 672 skewness coefficients for the unsmoothed PC2 and PC5 timeseries for the period of 1989-2011 are 
673 about 0.2 , and about 2 times greater for the period before 2000. The positive value of the skewness

674 indicates that more often SLP anomalies, having constituents similar to EOF2 and EOF5 patterns

675 presented in Fig. $8 b \underline{6 b}$ b, can be developed in the region under consideration.

676 The EOF analysis has revealed the best possible ENSO predictor for warm periods: it is PC5 that

677 is highly correlated with NINO3.4 ( 0.8) with lead time of 8 months. It means that processes in the

678 Southern Ocean due to air jet instability over the ACC during warm periods significantly contribute

679 to development of maximal phase of ENSO. One might argue that the conclusion stands on the

680 principle component PC5 which has only 5\% of total variance, and even if the PC5 correlates well

681 with ENSO with a 8-month lead, we cannot suggest that the SLP anomalies over the Southern Ocean

682 could have very significant effect on ENSO. However, it is well known that extreme events are

683 described by "probability distribution tail" that describes even less than $5 \%$ of all possible outcomes

684 (and ENSO can be considered such an event, since no regularity for ENSO events is observed

685 because, as was demonstrated by Eisenman et al. (2005), the wind anomalies considered in the

686 tropics are a combination of joint effects of stochastic atmospheric forcing and large-scale dynamics

687 (Eisenman et al. (2005))). It is worth noting that the pressure difference between centres of regions

688 with high and low pressure of EOF5 mode (Fig. 6c) is more than $50 \%$ of a similar difference of

689 EOF1 mode (Fig.6a). Thus PC5 describing only 5\% of total variance of SLP field can be significant

690 for ENSO forecast since it describes an appearance of plausible favourable conditions resulting in air

691 jet instability over the ACC that leads to different July-September SLP patterns in the Southern

692 Ocean (characterized by EOF2, explaining 14\% of total variance). It is worth noting alse that EOF3-

693

694 As was noted in the Introduction ENSO events could be considered as a consequence of changes

695 in the global meridional atmospheric circulation when the tropics and high latitudes interact with

696 each other rather than a local phenomenon. Since the interaction between the tropics and high

697 latitudes depends on the stochastic processes, which always occur during the interaction between the 
698 atmosphere and the ocean, time lag between atmospheric changes in the Southern Ocean and the 699 maximum phase of the development of ENSO is in a wide range of 3-5 months. Note here that the 700 primary component of stochastic forcing can be tropical intraseasonal variation, such as the Madden701 Julian Oscillation (MJO), Madden and Julian (1972), since MJO can impact the development ENSO 702 from the surface; it is likely that local atmospheric forcing is important to this type of ENSO, such as 703 those associated with the MJO. However, it is worth noting that Stepanov and Hughes (2006) have 704 shown that large-scale mass exchange exists not only between the Southern Ocean and Pacific. There 705 are also the Atlantic-Pacific and slightly weaker Indian-Pacific exchanges at shorter timescales 706 (periods from few days to 3 months). Therefore it is likely that this exchange can lead to the 707 appearance of some signals in the tropics and mid-latitudes of the Indian and Atlantic oceans too. 708 Hints of this can be seen in Fig. 3-7 presented by Stepanov (2009a) showing the model temperature 709 anomaly on the zonal section along the equator for the Indian Ocean too, which are due to the 710 variability of wind forcing over the ACC, together with the effect of bottom topography, though in 711 this experiment the forcing was defined as velocity disturbance was defined only for the meridional 712 component of the velocity only in the Pacific sector of the Southern ocean. It is likely that MJO and, 713 e.g., subtropical dipole variability in both the Southern Indian and Atlantic Oceans triggered by 714 Southern Hemisphere mid-latitude variability influencing ENSO found by Terray (2011), are the 715 results of such global inter-basin mass exchange. Further studies are needed to explore this 716 hypothesis.

717 During warmer periods, meridional gradients of the atmospheric dynamic characteristics that 718 decrease describe inter-latitudinal exchange, are weaker, therefore the SLP variability in the tropics 719 becomes weaker leading to the development of frequent but weak ENSO events (with SST anomalies 720 centered in the central equatorial Pacific). Interestingly, the observed result of frequent occurrence of 721 the "warm-pool El Niño" in the 2000s is consistent with coupled model simulations under global 722 warming by Yeh et al. (2009). 
723 In conclusion, it is worth noting that the results of the paper are in good agreement with Byshev et

724 al., (2012). They showed that the warm ENSO events are accompanied by the global atmospheric

725 oscillation when high atmospheric pressure is generated in the equatorial-tropical latitude band $726\left(\sim 45^{0} \mathrm{~N}-45^{0} \mathrm{~S} ; 60^{0} \mathrm{~W}-180^{\circ}\right)$, and a low atmospheric pressure develops over $2-3 \times 10^{3} \mathrm{~km}$ zone along 727 the outer boundaries of that structure. Thus, the magnitude of the meridional gradient of the zonal 728 wind speeds over the Southern Ocean is increasing, and favourable conditions for the onset of 729 instability of the air jet over the ACC are created leading to the appearance of blocking anticyclone 730 over the south-eastern part of the Pacific sector of the Southern Ocean. In the northern hemisphere, 731 the changes in the atmosphere, described by Byshev et al., (2012), may also lead to the appearance of 732 SST anomalies in the western North Pacific, which, according to Wang et al. (2012), can trigger 733 oceanic Kelvin waves, which propagate eastward and initiate the developments of ENSO.

734 Acknowledgements. The author would like to thank Keith Haines for his support in doing the work.

735 Thanks to Dr. N.Howe who carefully read the draft of the paper and provided helpful comments.

736 Comments from two anonymous reviewers helped to significantly improve the manuscript. This 737 work was supported by the NCEO and the RAPID -Watch Valor projects. 738 


\section{References}

740 1. Alexander, M. A., L. Matrosova, C. Penland, J. D. Scott, and P. Chang (2008), Forecasting

741 Pacific SSTs: Linear inverse model predictions of the PDO, J. Clim., 21, 385-402, 742 doi:10.1175/2007JCLI1849.1.

$$
\text { 2. F. Alvarez-Garcia, W. C. Narvaez, and M. J. Ortiz Bevia (2006), An Assessment of }
$$

Differences in ENSO Mechanisms in a Coupled GCM Simulation, J. Climate 19 (1), $69-87$.

745

746 nection patterns in austral winter, J. Atmos. Sci. 52(21), 3661-3672, DOI: 10.1175/1520-0469(1995)

$747 \quad 052<3661:$ RWPATP $>2.0 . \mathrm{CO} ; 2$

748 4.3. Ashok, K., S. K. Behera, S. A. Rao, H. Weng, and T. Yamagata (2007), El Niño Modoki and

749 its possible teleconnection, J. Geophys. Res., 112, C11007, doi:10.1029/2006JC003798.

750 5. Battisti, D., and A. C. Hirst (1989) Interannual variability in a tropical atmosphere-ocean

751 model: Influence of the basic state, ocean geometry and nonlinearity, J. Atmos. Sei., 46, 1687 1712.

752 6.4. Blaker, A.T., B. Sinha, V.O. Ivchenko, N.C. Wells, and V.B. Zalesny (2006) Identifying the

753 roles of the ocean and atmosphere in creating a rapid equatorial response to a Southern Ocean

754 anomaly, Geophysical Research Letters, v.33, L06720, doi:10.1029/2005GL025474.

755 7.5. Bretherton, C. S., M. Widmann, V.P. Dymnikov, J. M. Wallace, and I. Bladẻ (1999) The

756 effective number of spatial degrees of freedom of a time-varying field, J. Climate, 12(7), 1990-2009.

757 8.6. V.I.Byshev, V.G.Neyman, Yu.A.Romanov and I.V.Serykh, El Niño as a consequence of the

758 Global Oscillation in the dynamics of the Earth's climate system// Doklady Earth Scienses, 2012 , vol.

759 446, Part 1, pp. 1089-1094.

760 9.7. Carleton A.M (2003), Atmospheric teleconnections involving the Southern Ocean, J. of

761 Geophysical Research, 108(C4), DOI: 10.1029/2000JC000379. 
763 Tippett (2007), Pacific meridional mode and El Niño-Southern Oscillation, Geophys. Res. Lett., 34,

764 L16608, doi:10.1029/2007GL030302.

765 11.9. Clarke, A. J., and S. Van Gorder (2003) Improving El Niño prediction using a space-time

766 integration of Indo-Pacific winds and equatorial Pacific upper ocean heat content, Geophys. Res. Lett.,

767 30(7), 1399, doi:10.1029/2002GL016673.

768 12. Close S.E and A.C. Naveira Garabato (2012) Barøclinic adjustment in Drake Passage driven

769 by tropical Pacific forcing, Geophys. Res. Lett., 39, L19610, doi:10.1029/2012GL053402.

770 13.10. Deleroix T., J. Picaut and G. Eldin (1991) Equaterial Kelvin and Rossby waves

771 evidenced in the Pacific Ocean through geosat sea level and surface current anomalies, J. of

772 Geophysical Research, 96(CSupplemen), 3249-3262, 10.1029/90JC01758.de Viron O., J. O. Dickey,

773 and M. Ghil (2013), Global modes of climate variability, Geophys. Res. Lett., 40, $1832-1837$.

774 doi:10.1002/grl.50386.

775 14.11._Dong, B., R.T. Sutton, and A.A. Scaife (2006) Multidecadal modulation of El Niño-

776 Southern Oscillation (ENSO) variance by Atlantic Ocean sea surface temperatures, Geophysical

777 Research Letters, v.33, L08705, doi:10.1029/2006GL025766.

$778 \quad 15.12$ E_ Eisenman I., L. Yu, E. Tziperman (2005) Westerly Wind Bursts: ENSO’s tail rather

779 than the dog?, J. Climate, 18, 5224-5238.

780 16.13. Flügel M., P. Chang, C. Penland (2004) The role of stochastic forcing in modulating

781 ENSO predictability, J. Climate, 17, 3125-3140.

782 14. Gill, A. E., 1982: Atmosphere-Ocean Dynamics. Academic Press, 662 pp.

783 17.15. Henderson-Sellers A., H. Zhang, G. Berz, K. Emanuel, W. Gray, C. Landsea, G.

784 Holland, J. Lighthill, S-L. Shieh, P. Webster, and K. McGuffie (1998) Tropical cyclones and global

785 climate change: A post-IPCC assessment, Bulletin of the American Meteorological Society 79(1),

786 p.19-38. doi: http://dx.doi.org/10.1175/1520-0477(1998)079<0019:TCAGCC>2.0.CO;2. 

Horii T., I. Ueki, and K. Hanawa (2012) Breakdown of ENSO predictors in the 2000s:

788 Decadal changes of recharge/discharge-SST phase relation and atmospheric intraseasonal forcing, 789 Geophys. Res. Lett., 39, L10707, doi:10.1029/2012GL051740.

\begin{tabular}{l|l}
790 & 19. Ibraev R.A. (1993) Reconstruction of Climatic Characteristics of the Gulf Stream Current," \\
791 & Izvestiya AN, Fizika Atmosfery i Okeana 29 (6), 803 814. \\
792 & $20.17 . \quad$ Ivchenko V.O., V. B. Zalesny, and M.R. Drinkwater (2004) Can the equatorial ocean
\end{tabular} 793 quickly respond to Antarctica sea ice/salinity anomalies?, Geophysical Research Letters, v.31, L15310, 794 doi:10.1029/2004GL020472.

795 21.18. Ivchenko V.O., V. B. Zalesny, and M.R. Drinkwater and J. Schröter (2006) A quick 796 response of the equatorial ocean to Antarctic sea ice/salinity anomalies, J. of Geophysical Research, 797 vol. 111, C10018, doi:10.1029/2005JC003061.

798 19. Jin, F.-F. (1997) An equatorial recharge paradigm for ENSO. Part I: Conceptual model. J. 799 Atmos. Sci., 1997, V.54, p. 811-829.

800 20. Kao, H.-Y., and J.-Y. Yu, 2009: Contrasting eastern-Pacific and central-Pacific types of 801 ENSO. J. Climate, 22, 615-632.

802 22.21. Kug, J.-S., F.-F. Jin, and S.-I. An (2009), Two types of El Niño events: Cold Tongue 803 El Niño and Warm Pool El Niño, J. Clim., 22, 1499-1515, doi:10.1175/2008JCLI2624.1.

804 23. Kwok, R. and J.C. Comiso (2002) Southern Ocean climate and sea ice anomalies associated 805 with the Southern Oscillation, J. Climate, 15, 487501.

806 24.22. Larkin, N. K., and D. E. Harrison (2005), Global seasonal temperature and 807 precipitation anomalies during El Niño autumn and winter, Geophys. Res. Lett., 32, L16705, 808 doi:10.1029/2005GL022860.

809 25.23. Lau N.-C., A. Leetmaa, M.J. Nath, H.-L. Wang (2005) Influence of ENSO-induced 810 Indo-Western Pacific SST anomalies on extratropical atmospheric variability during the boreal 811 summer, Climate, 18, 2922-2942. 
813 equatorial Pacific, Geophys. Res. Lett., 37, L14603, doi:10.1029/2010GL044007.

814 27.25. Lengaigne M., E. Guilyardi, J.-P. Boulanger, C. Menkes, P. Delecluse, P. Inness,

815 J.Cole, J. Slingo (2004) Triggering of El Niño by westerly wind events in a coupled general circulation

816 model, Climate Dynamics, 23, 601-620, doi:10.1007/s00382-004-0457-2.

817 28. L'Heurex M.L and D.W.J. Thompson (2006) Observed Relationships between the El Niño-

818 Southern Oscillation and the Extratropical Zonal Mean Circulation, J. Climate. V. 19. p. 276287.

819 29.26. Madden, R. A., and P. R. Julian (1972), Description of global scale circulation cells in

820 the tropics with a 40-50-day period, J. Atmos. Sci., 29, 1109-1123, doi:10.1175/1520-

821 0469(1972)029<1109:DOGSCC>2.0.CO;2.

822 30.27._McPhaden, M. J. (2003) Tropical Pacific Ocean heat content variations and ENSO 823 persistence barriers, Geophys. Res. Lett., 30(9), 1480, doi:10.1029/2003GL016872.

824 31.28. McPhaden, M. J., X. Zhang, H. H. Hendon, and M. C. Wheeler (2006) Large-scale 825 dynamics and MJO forcing of ENSO variability, Geophys. Res. Lett., 33, L16702, 826 doi:10.1029/2006GL026786.

827 32.29. Mo K.C. and M. Ghil (1987), Statistics and dynamics of persistent anomalies, J. 828 Atmos. Sci., 44(5), DOI:10.1175/1520-0469(1987)044<0877:SADOPA>2.0.CO;2

829 33.30._Mokhov I.I., and D.A. Smirnov (2006) El Niño-Southern Oscillation drives North 830 Atlantic Oscillation as revealed with nonlinear techniques from climatic indices, Geophysical Research 831 Letters, v.33, L03708, doi:10.1029/2005GL024557.

832 34.31._Müller W.A., and E. Roecker (2006) ENSO impact on midlatitude circulation patterns 833 in future climate change projections, Geophysical Research Letters, v.33, L05711, 834 doi:10.1029/2005GL025032.

835 32. Nicholls N., H.-J. Baek, A. Gosai, L.E. Chambers, Y. Choi, D. Collins, P.M. Della-Marta, 836 G.M. Griffiths, M.R. Haylock, N. Iga, R. Lata, L. Maitrepierre, M.J. Manton, H. Nakamigawa, N. 
837 Ouprasitwong, D. Solofa, L. Tahani, D.T. Thuy, L. Tibig, B.Trewin, K. Vediapan, and P. Zhai (2005)

838 The El Niño-Southern Oscillation and daily temperature extremes in east Asia and the west Pacific,

839 Geophysical Research Letters, v.32, L16714, doi:10.1029/2005GL022621.

840 35.33. Overland, J. E., and R.W. Preisendorfer (1982), A significance test for principal

841 components applied to cyclone climatology, Mon. Wea. Rev., 110, 1-4.

842 36.34. Paldor N., and Y. Dvorkin (2006) Barotropic Instability of a Zonal Jet: From

843 Nondivergent Perturbations on the $\beta$-Plane to Divergent Perturbations on a Sphere, J. Phys. Oceanogr.,

$84436,2271-2282$.

845 37.35. Pierce, D. W., T. P. Barnett, and M. Latif (2000), Connections between the Pacific

846 Ocean tropics and midlatitudes on decadal timescales, J. Clim., 13, 1173-1194, doi:10.1175/1520-

847 0442(2000)013<1173:CBTPOT>2.0.CO2.

848 38. Richardson G., M. R. Wadley, K. Heywoed, D. P. Stevens, and H. T. Banks (2005) Short-

849 Term Climate Response to a Freshwater Pulse in the Southern Ocean," Geophys. Res. Lett. 32 ,

L03702, doi:10.1029/2004GL021586.

851 39. Simmonds, I., and T. H. Jacka (1995) Relationship between the interannual variability of

Antaretic sea ice and the Southern-Oscillation, J. Climate, 8, 637647.

40.36. Sinclair M.R, J.A. Renwick and J.W. Kidson (1997), Low-Frequency Variability of

854 Southern Hemisphere Sea Level Pressure and Weather System Activity, Mon Wea Rev, 125(10), DOI:

855 10.1175/1520-0493(1997)125<2531:LFVOSH>2.0.CO;2.

\begin{tabular}{l|l}
856 & 41. Stepanov V. N. and C. W. Hughes (2004) The Parameterization of Ocean Self Attraction and \\
857 & Loading in Numerical Models of the Ocean Circulation, J. Geophys. Res. 109, C0037, \\
858 & dei:10.1029/2003JC002034. \\
859 & $42.37 . \quad$ Stepanov V.N. and C.W. Hughes (2006) Propagation of signals in basin-scale bottom
\end{tabular}

860 pressure from a barotropic model, J. Geophys. Res., 111, C12002, doi:10.1029/2005JC003450. 
862 and its link with the ENSO events. Oceanology, Vol. 49, No. 1, pp. 5-19

44.39. Stepanov V.N. (2009b) The modelling of the ENSO events using a simple model.

864 Oceanology, Vol. 49, No. 3, pp. 310-319.

865 45.40. Stepanov V.N., H. Zuo, K. Haines (2012) The link between the Barents Sea and

866 ENSO events simulated by NEMO model. Ocean Sciences, 8, 971-982, doi:10.5194/os-8-971-2012.

867 46. Suarez M. and P. S. Schopf (1988) A Delayed Action Oscillator for ENSO, J. Atmos. Sci. 45

$868(21), 3283-3287$.

869 41. Terray P. (2011) Southern Hemisphere extra-tropical forcing: a new paradigm for El Niño -

870 Southern Oscillation, Clim Dyn (2011) 36:2171-2199, DOI 10.1007/s00382-010-0825-z.

871 47.42. Trenberth K.E. 1997. The definition of El Niño. Bulletin of the American

872 Meteorological Society 78(12): 2771-2777.

873 48.43. Vimont, D. J., J. M. Wallace, and D. S. Battisti (2003a), The seasonal footprinting

874 mechanism in the Pacific: Implications for ENSO, J. Clim., 16, 2668-2675, doi:10.1175/1520-

875 0442(2003)016<2668:TSFMIT>2.0.CO2.

876 49-44. Vimont, D. J., D. S. Battisti, and A. C. Hirst (2003b), The seasonal footprinting

877 mechanism in the CSIRO general circulation models, J. Clim., 16, 2653-2667, doi:10.1175/1520-

878 0442(2003)016<2653:TSFMIT>2.0.CO2.

879 50.45. Wang S.-Yu, M. L'Heureux, and H.-H. Chia (2012) ENSO prediction one year in 880 advance using western North Pacific sea surface temperatures, Geophys. Res. Lett., 39, L05702,

881 doi:10.1029/2012GL050909.

\begin{tabular}{l|c}
882 & 51. Weisberg, R. H., and C. Wang (1997) A western Pacific oseillator paradigm for the E1 Niño- \\
883 & Southern Oscillation. Geophys. Res. Lett., 24, 779-782. \\
884 & $52.46 . \quad$ Yeh, S.-W., J.-S. Kug, B. Dewitte, M.-H. Kwon, B. Kirtman, and F.-F. Jin (2009), El \\
885 & Niño in a changing climate, Nature, 461, 511-514, doi:10.1038/nature08316
\end{tabular} 


\section{List of Figure Captions}

891 Fig. 1. 1989-2009 correlations of zonally averaged sea level pressure with SOI-index with negative

892 signs (a), and (b) with the zonally averaged sea level pressure difference between $17^{\circ}$ and $12^{\circ} \mathrm{S}$.

893 Positive lags means that the zonally averaged sea level pressure lags from corresponding time series.

894 (c) - time series of SOI-index with negative signs (red), zonally averaged sea level pressure

895 difference between $17^{\circ}$ and $12^{\circ} \mathrm{S}$ (blue), and zonally averaged sea level pressure difference between

$89617^{\circ}$ and the equator (green); d) - the same as c) but the seasonal cycle was removed and low-pass

897 filtering with periods longer than 18 months was applied.

898 Fig. 2. The values of transport through Drake Passage in Sv (thin solid line) and variability of

$\left.899 M(t)\right|_{\varphi=40 s}$-due to meridional transport fluctuations through the latitude of $40^{\ominus} \mathrm{S}$ in the Pacific Ocean in

900 Gt (thick solid line) averaged for July-September. Symbols EL and LA denote warm and cold ENSO

901 events, respectively. Dashed line corresponds to scaled winter's NINO4 index.

902 Fig. 3. The temperature anomaly on the zonal section along the equator at three consecutive times

$903(t=90,120$ and 150 days $)$. The units are in ${ }^{\ominus} \mathrm{C}$. The horizontal dashed line shows the depth of $300 \mathrm{~m}$.

904 Fig. 4. 1989-2011 mean (a) and standard deviation (b) of sea level pressure, and correlations (c)

905 between SAM index and sea level pressure for the same period. The dashed black line on Fig. $4 \mathrm{c}-\underline{2 c}$

906 shows a zone of divergence (convergence) of the meridional mass fluxes according to Stepanov

907 (2009a). the boundary between the regions, in which atmospheric cyclones south of $48^{\circ} \mathrm{S}$ and

908 anticyclones north of $47^{\circ} \mathrm{S}$ propagate in the eastern direction over the ACC. The black cross denotes

909 the position $\left(280^{\circ} \mathrm{E}\right.$ and $\left.35^{\circ} \mathrm{S}\right)$ chosen to monitor the sea level pressure variability.

910 Fig. 53. Sea level pressure anomaly (in HPa) for July-September mean of 1997 (a), 2002 (b), 1998

911 (c) and for August-October mean of 2007 (d) before the maximum phase of the development of

912 warm (a, b) and cold (c, d) ENSO. 
913 Fig. 6.

914 (black dashed) and the averaged sea level pressure along $280^{\circ} \mathrm{E}$ between $35^{\circ} \mathrm{S}$ (the point marked by

915 black cross on Fig. $4 \mathrm{c}$ ) and $45^{\circ} \mathrm{S}, \Delta p$, (solid). The black solid line is after applying 5 month running

916 average procedure and it is shifted 4 months forward; the seasonal cycle was subtracted.

917 Fig. 7․ 1989-1999 (a) and 2000-2008 (b) standard deviations of sea level pressure (in Hpa); c-d -

918 the same as a-b, but normalized on 1989-2011 mean standard deviations, and shown in enlarged scale

919 for the tropics; e-f the same as c-d but for 2000-2007 and 2008-2011 periods respectively.

920 Fig. 8‥ EOF1 (a), EOF2 (b) and EOF5 (c) modes of the Southern ocean region SLP (1989-2011)

921 multiplied by respective standard deviations of the principal components (units in Hpa). Normalized

922 time series (solid line) of PC1 (d), PC2 (e) and PC5 (f) together with the time series of the NINO3.4

923 index (dashed line, after applying 5 month running average procedure) are also shown. PC1, PC2 and

924 PC5 are after applying 5 month running average procedure and they are shifted forwards by 1,4 and 9258 months respectively.

926

927 


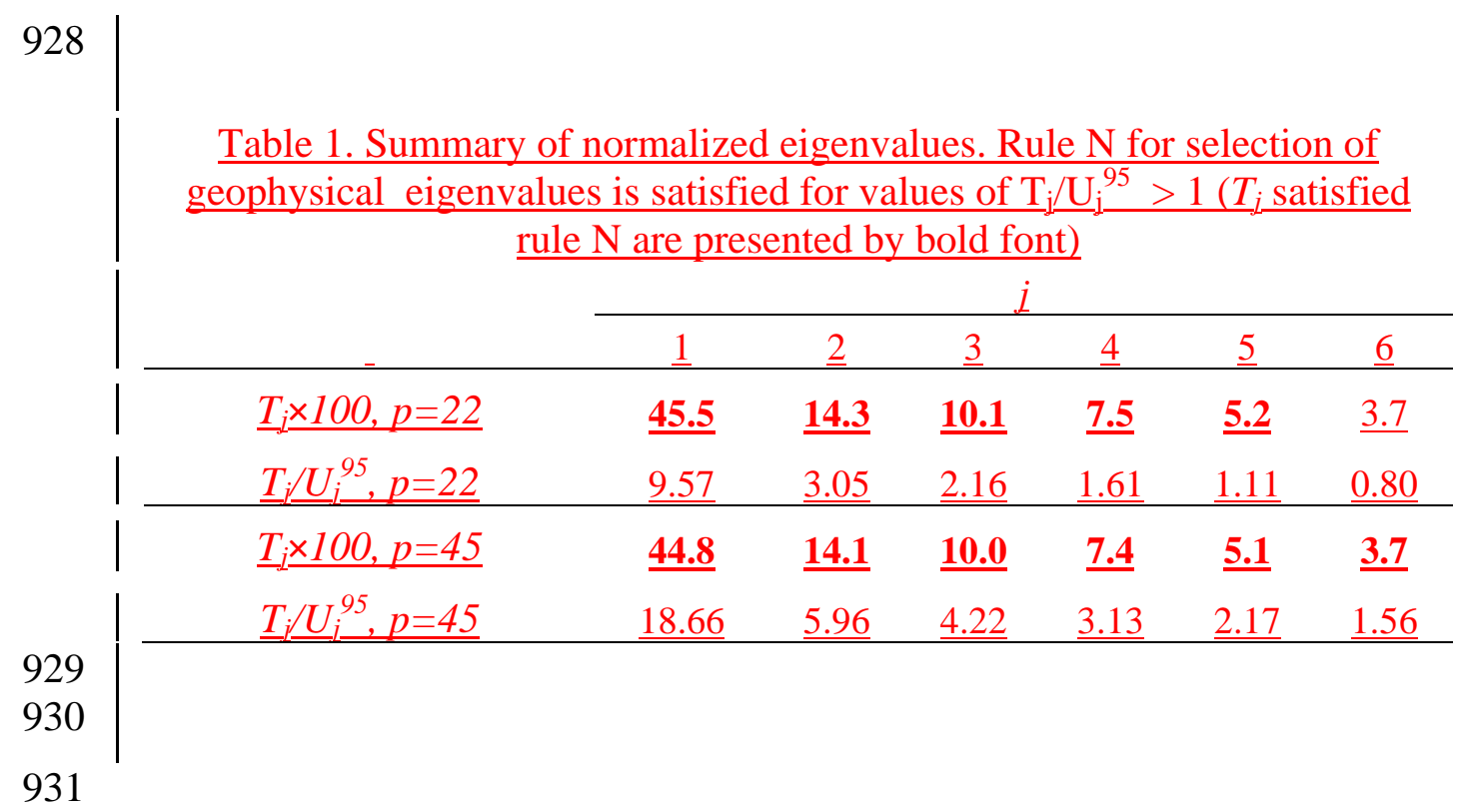

